\title{
DEMAND, COST ELASTICITIES AND PRICING BENCHMARKS IN THE HYPOTHETICAL MONOPOLY TEST : THE CONSEQUENCES OF A SIMPLE SSNIP
}

\author{
by
}

\author{
Ian M Dobbs \\ The Business School, \\ University of Newcastle upon Tyne.
}

KEYWORDS: Hypothetical Monopoly Test, SSNIP test, Significant Market Power.

JEL CLASSIFICATION: L41, L42, L5.

Last Revised: 5 July 2002 


\begin{abstract}
The hypothetical monopoly test for market power is translated into an operational 'formula' involving cost and demand elasticities. The importance of the choice of the pricing benchmark is emphasised - and of why it is important to incorporate an assessment of cost structure when conducting such tests. Recent work in the EU and the UK (notably in Telecoms) has ignored cost structures when making assessments of market power. It is shown in this paper that ignoring cost structure leads to bias in that market power will often be found when in fact none is present.
\end{abstract}




\section{INTRODUCTION}

Following the publication of the US Department of Justice Merger Guidelines (DOJ [1984]), the concept of a 'hypothetical monopoly test' (HMT) has become a cornerstone for the regulatory assessment of market power and for defining antitrust market boundaries. This has been true for some in the US, but is now also being put centre stage in EU directives and guidelines (see EU [2002]). Academic work on the implementation of the HMT has tended to focus on the degree of substitutability with potentially competitive products (see e.g. market reviews in OFTEL [2000,2002a,b]) or been concerned with the assessment of critical elasticity or critical sales loss for the single product case (see e.g. Harris and Simons [1989], Werden [1998], Hausman, Sidak and Singer [2001], Massey [2001], Langenfeld and Li [2001]) although the extension to the assessment of market power and market boundaries in multi-product market settings has also recently been studied (Dobbs [2001]).

This paper revisits the single product HMT. An initial purpose is to give a formal derivation of an operational rule, clearly specifying the assumptions that underpin it (this, in itself is only a minor tightening up of work already done in the literature cited above). Following this, the critical role of the pricing benchmark is examined, and the importance of an assessment of cost elasticity emphasised. This is followed by an assessment of the kind of bias that arises if cost structure is ignored in the application of the test in assessments of market power (as is the case in recent market reviews in UK Telecoms).

The 'hypothetical monopoly test' (HMT) is explained in the US department of Justice horizontal merger guidelines (DOJ [1984]) as follows: 
"Formally, a market is defined as a product or a group of products and a geographical area in which it is sold such that a hypothetical, profit maximising firm, not subject to price regulation, that was the only present and future seller of those products in that area would impose a 'small but significant and non-transitory' increase in price above prevailing or likely future levels." (bold italics added)

The HMT is often referred to, acronymically, as a SSNIP test (SSNIP deriving from the words in italics in the above definition). In practice it is common to set a specific level of price increase - typically 5\%. In what follows we shall refer to the test as an $\alpha \%$ SSNIP test where, for example, $\alpha=0.05$ corresponds to a 5\% SSNIP test. The minimal threshold for the test is clearly that of the 0\%SSNIP test - in this case there is market power if an arbitrarily small price increase is profitable. Section 2 presents the analysis and section 3 draws together some conclusions.

\section{HMT RULES OF THUMB}

Let the price per unit output be $p$, the demand at this price be denoted $q(p)$ and the total cost of producing this output $q$ be denoted $C(q)$, so that profit $\pi$ is given as

$$
\pi(p)=p q(p)-C(q(p))
$$

Suppose there is an initial benchmark price $p_{0}$ at which the HMT is to be

implemented. The HMT involves raising price from $p_{0}$ to $p_{1}=(1+\alpha) p_{0}$ where $\alpha$ is the level set for the SSNIP test. Taking an exact third order Taylor series expansion of $\pi(p)$ around the point $p_{0}$ gives

$$
\pi\left(p_{1}\right)=\pi\left(p_{0}\right)+\pi^{\prime}\left(p_{0}\right)\left(\alpha p_{0}\right)+\frac{1}{2} \pi^{\prime \prime}\left(p_{0}\right)\left(\alpha p_{0}\right)^{2}+\frac{1}{6} \pi^{\prime \prime \prime}(\tilde{p})\left(\alpha p_{0}\right)^{3}
$$

where $\tilde{p}$ is some point intermediate $p_{0}$ and $p_{1}$.

Assumption (Local Linearity): It is assumed that demands and marginal costs are locally linear on the range $\left(p_{0}, p_{1}\right)$; that is, $q^{\prime \prime}(p)=0$ and $C^{\prime \prime}(q(p))=0$ for $p \in\left(p_{0}, p_{1}\right)$. 
Before continuing, it is worth emphasising that this is not a particularly restrictive assumption to impose. The price change is relatively small in practice (5 or $10 \%$ changes are typically considered); thus it can be expected that the results obtained below will hold to good approximation even if the assumption does not exactly hold.

It is convenient to write $m=\left(p_{0}-C^{\prime}\left(q\left(p_{0}\right)\right)\right) / p_{0}$ as the mark-up of price over marginal cost, and write $\eta=q^{\prime}\left(p_{0}\right)\left(p_{0} / q_{0}\right)$ as the own price elasticity of demand, where both are evaluated at the benchmark price. Under local linearity, it is straightforward to show that $\pi^{\prime}\left(p_{0}\right)=q_{0}[1+m \eta]$, that $\pi^{\prime \prime}\left(p_{0}\right)=2 q^{\prime}\left(p_{0}\right)$ and that $\pi^{\prime \prime \prime}(\tilde{p})=0$ (see appendix). Substituting these results into (2) and rearranging, the change in profit can be then be expressed as

$$
\Delta \pi=\pi\left(p_{1}\right)-\pi\left(p_{0}\right)=p_{0} q_{0}\left[(1+m \eta) \alpha+\eta \alpha^{2}\right]
$$

Thus an $\alpha \%$ increase in price is profitable if

$$
(1+m \eta) \alpha+\eta \alpha^{2}>0 \Rightarrow \alpha<-(1+m \eta) / \eta
$$

(recall $\eta<0$; demand curves are assumed to have negative slope). ${ }^{1}$ This condition is now examined for two candidate benchmarks

\section{(a) the 'marginal cost pricing' benchmark}

Under perfect competition, at equilibrium price equals marginal cost (equals average cost), so $p_{0}=C^{\prime}\left(q\left(p_{0}\right)\right)$ and $m=0$. In this case, (4) simplifies to

\footnotetext{
${ }^{1}$ The 'critical elasticity' ( $\left.\eta^{\text {crit }}\right)$ and 'critical sales loss' $(C S L)$, which make the test just marginal, and which are discussed in earlier literature (such as Harris and Simons [1989], Werden [1998], Hausman et al [2001]), follow immediately from this condition. That is, setting (4) as an equality and rearranging, $\eta^{\text {crit }}=-1 /(m+\alpha)$, and since from the definition of elasticity, $\eta^{\text {crit }}=C S L / \alpha$, so $C S L=-\alpha /(m+\alpha)$. It is also possible to define other 'critical values', including the 'critical markup' etc. - these variations are discussed in more detail in Dobbs [2001] which also deals with the multiproduct case.
} 


$$
\alpha<-1 / \eta
$$

If we ask if some raising of price is profitable in a perfectly competitive market, the answer is always yes (clearly setting $\alpha$ arbitrarily small, equation (5) will necessarily be satisfied). That is,

Proposition 1: Under local linearity, with a marginal cost pricing benchmark, there is always some market power detected under a ZERO\%SSNIP test.

Inverting equation (5), this also implies:

Proposition 2: Under local linearity, with a marginal cost pricing benchmark, there is market power under an $\alpha \%$ SSNIP test iff $\eta>-1 / \alpha$.

Thus, to assess market power under the HMT using a 'perfect competition' benchmark of marginal cost pricing, all that is required is an assessment of demand elasticity. A 5\% rise in price is profitable, from proposition 2, if demand is more inelastic than -20; i.e. if $\eta>-20$. Likewise, under a 10\% SSNIP test, a rise in price would be profitable if $\eta>-10$ and so on. Thus, demand has to be really quite elastic for the HMT SSNIP test NOT to find market power.

\section{(b) the 'average cost pricing' benchmark}

In practice the usual reason the market is under investigation is because of suspicion that there is indeed some degree of market power - and it is precisely in such circumstances that the technology is likely to not support perfect competition. That is, in most applications, marginal cost $(M C)$ will not be equal to average cost $(A C)$ at the output level at which price equals average cost (but will lie below it). In such 
circumstances, the obvious candidate for a 'quasi-competitive' benchmark is that of average cost. $^{2}$ Thus, setting $p=A C$, the mark-up is given as

$$
m=\frac{p-M C}{p}=1-\frac{M C}{A C}
$$

The ratio MC/AC is sometimes referred to as an index of cost flexibility. ${ }^{3}$ It can be immediately connected to various elasticity concepts, notably the cost elasticity and the elasticity of scale as follows. Cost elasticity, $\mathcal{E}_{c}$, is defined as

$$
\varepsilon_{c} \equiv(d C / d q)(q / C)=M C / A C
$$

whilst, assuming cost efficient input choices, it is also the case that this is equal to the inverse of the scale elasticity $\varepsilon_{\text {scale }}$; that is $\mathcal{E}_{c}=1 / \mathcal{E}_{\text {scale }}$ (see Chambers [1988, p. 72] or Varian [1992]). ${ }^{4} \quad$ The condition can thus be written as:

Proposition 3: Under local linearity, with an average cost pricing benchmark, there is market power under an $\alpha \%$ SSNIP test iff $\eta>-1 /\left[\alpha+1-\varepsilon_{c}\right]$ (assuming cost efficiency, iff $\eta>-1 /\left[\alpha+1-\left(1 / \varepsilon_{\text {scale }}\right)\right]$ ).

Under constant returns to scale, $\varepsilon_{\text {scale }}=1$ and $\varepsilon_{c}=M C / A C=1$ and proposition 3 simplifies to proposition 2. Thus, in the absence of fixed costs or other non-linearities in production, the HMT assessment of market power can be determined by exclusive

\footnotetext{
${ }^{2}$ The price that would hold in a contestable market, for example (see Baumol et al [1982]).

${ }^{3}$ See e.g. Chambers [1988, p. 69].

${ }^{4}$ If the underlying production function is defined as $f(\mathbf{x})$ where $\mathbf{x}$ denotes a vector of inputs, then the elasticity of scale is defined as $\varepsilon_{\text {scale }}=d(\ln f(\lambda \mathbf{x})) /\left.d(\ln \lambda)\right|_{\lambda=1}$. That is, it measures how output varies at a given input vector as all inputs are expanded proportionately. The connection with cost elasticity $\mathcal{E}_{c}$ holds only if the input vector under consideration is, for the output it produces, in fact a cost minimising input vector.
} 
referral to demand elasticity. At the other extreme, when fixed costs are very important and marginal costs are small, $\varepsilon_{c}=M C / A C \rightarrow 0$ and proposition 3 simplifies to the condition

$$
\eta>-\frac{1}{\alpha+1}
$$

Notice that, for the relatively small values of $\alpha$ normally used in the SSNIP test 0.05 or 0.1 ), this is close to requiring $\eta>-1$ for there to be market power. That is, to find market power when there are heavy fixed costs relative to variable costs, demand has to be really quite close to being inelastic.

Outside of these extreme cases $\left(\varepsilon_{c}=M C / A C=1\right.$, or $\left.\varepsilon_{c}=M C / A C=0\right)$, as one would expect, any assessment of market power requires not only an assessment of demand elasticity but also of cost elasticity - the extent of cost flexibility.

\section{CONCLUDING COMMENTS}

The principal motivation behind the present note is a practical concern. The EU Commission has recently issued a set of directives which aims to establish a framework for the regulation of telecommunication network and services throughout the EU and consultation is now under way on how these directives are to be translated into guidelines for national regulatory authorities regarding the imposition of ex ante regulation (see EU [2002], OFTEL [2002a]). It would appear from these documents that the hypothetical monopoly test is likely to feature quite heavily in the assessment 
of significant market power (SMP) and that SMP may well be used as a trigger for regulation.

There are many concerns with the application of the HMT in innovative markets (and Telecommunications is clearly a prime example). ${ }^{5}$ However, even within its own terms, there are concerns regarding the way market power is being assessed by (EU) regulatory authorities when they claim to be using the HMT framework. Regulators are often explicit in indicating that they are invoking the HMT when conducting market reviews and assessments of whether a product should be classified as having SMP. However, in such reviews, the analysis is typically based on intuitive assessments of qualitative 'substitution possibilities', without any effort being made to translate these into estimates of own price demand elasticity. Furthermore, very little attention is being paid to cost structure in such assessments.

For example, a recent OFTEL [2000, 2002b] market review (of broadband internet access) assessed the situation as one in which there was significant market power without any attempt to go beyond discussion at the qualitative level of 'substitution possibilities'. The OFTEL analysis of the extent of substitutability was commendable in its detail - however, no attempt was made to translate this back into an estimate of own price elasticity. Furthermore, there was no discussion of the other critical parameter - namely, the cost elasticity. Arguably, for broadband internet access, the cost elasticity might well be closer to zero than to unity (in a US assessment of internet access, Hausman et al [2001] for example take it to be zero). On the above analysis, if that were the case in the UK, one would almost certainly find that there was no significant market power with respect to Broadband internet access under the hypothetical monopoly test. Thus an assessment regarding the cost 
structure can be critical regarding the outcome of a market review. By ignoring cost structure (implicitly setting the cost elasticity at unity, when it will tend to take a lower value), there is a clear direction to the bias this makes in the HMT. That is, the bias is in the direction of the market review finding significant market power when in fact there is none.

Overall, the thrust of the analysis in this paper is a conditional one. If the HMT is to be invoked, then the assessment of market power should involve an examination of both demand and cost considerations. In the above analysis, the assessment was tied to two key parameters, namely the own price elasticity of demand and the cost elasticity. When regulatory authorities ignore cost structures in their assessment of 'significant market power', this is a legitimate concern, precisely because the bias in doing so is toward that of finding more SMP than there really is.

\section{REFERENCES}

Baumol W.J., Panzar J.C. and Willig R.D., 1982, Contestable markets and the theory of industry structure, Harcourt Brace Jovanovich, New York.

Chambers R.G., 1988, Applied production analysis: a dual approach, Cambridge University Press, Cambridge UK.

Dobbs I.M., 2001, The assessment of market power and market boundaries using the hypothetical monopoly test, Discussion Paper 2001/2, The Business School, University of Newcastle upon Tyne.

EU, 2002, European Union - Commission services working document: Draft guidelines on market analysis and the assessment of significant market power under the Community regulatory framework for electronic communications networks and services, 21/2/2002.

Harris B.C. and Simons J.J., 1989, Focusing market definition: how much substitution is necessary?, Research in Law and Economics, 12, 207-226.

\footnotetext{
${ }^{5}$ See for example Hartman et al [1993].
} 
Hartman, Teece Mitchell, and Jorde, 1993, Assessing market power in regimes of rapid technological change,' Industrial and Corporate Change, 31, 323-24 .

Hausman J.A., Sidak J.G. and Singer H.J., 2001, Residential demand for broadband telecommunications and consumer access to unaffiliated internet content providers, Yale Journal on Regulation, 18, 129-173.

Lind R.C., Muysert P., and Walker M., 2002, Innovation and competition policy, Economic Discussion Paper 3, Office of Fair Trading, London (Web-address: http://www.oft.gov.uk)

Massey P., 2000, Market definition and market power in competition analysis: Some practical Issues, The Economic and Social Review, 4, 309-328.

OFT, 1998, A guide to the provisions of the Competition Act 1998: Market Definition, Office of Fair Trading, London, (Web-address: http://www.oft.gov.uk)

OFTEL, 2000, Consultation on the future interconnection arrangements for dial-up internet in the UK, November 2000, (available from the web-site: http://www.oftel.co.uk)

OFTEL, 2002, Imposing access obligations under the new EU directives, A consultation on guidelines (available from the web-site: http://www.oftel.co.uk)

OFTEL, 2002, Direction to resolve a dispute between BT, Energis and Thus concerning xDSL interconnection at the ATM switch, 14 June (available from the web-site: http://www.oftel.co.uk).

US Department of Justice and the Federal Trade Commission, 1984, Horizontal Merger Guidelines, Washington DC. Revised: 1994, 1997. (website: http://www.usdoj.gov)

Varian H., 1992, Microeconomic Analysis, 3rd Ed., Norton, New York.

Werden G.J., 1998, Demand elasticities in anti-trust analysis, Antitrust Law Journal, 66, 363-414. 


\section{APPENDIX}

Derivations (worth including? - could be omitted)

Recall

$$
\pi(p)=p q(p)-C(q(p))
$$

and $\eta \equiv \frac{p_{0} q^{\prime}\left(p_{0}\right)}{q\left(p_{0}\right)}$ and $m \equiv \frac{p_{0}-C^{\prime}\left(q\left(p_{0}\right)\right)}{p_{0}}$.

Hence

$$
\begin{aligned}
& \pi^{\prime}(p)=q(p)+\left[p-C^{\prime}(q(p))\right] q^{\prime}(p) \\
& =q(p)\left\{1+\left[\frac{p-C^{\prime}(q(p))}{p}\right] \frac{p q^{\prime}(p)}{q(p)}\right\}
\end{aligned}
$$

and so

$$
\pi^{\prime}\left(p_{0}\right)=q\left(p_{0}\right)\{1+m \eta\} .
$$

From this,

$$
\begin{aligned}
& \pi^{\prime \prime}(p)=d / d p\left[q(p)+\left[p-C^{\prime}(q(p))\right] q^{\prime}(p)\right] \\
& =q^{\prime}(p)+\left[p-C^{\prime}(q(p))\right] q^{\prime \prime}(p)+\left[1-C^{\prime \prime}(q(p)) q^{\prime}(p)\right] q^{\prime}(p) \\
& =2 q^{\prime}(p)
\end{aligned}
$$

for $p \in\left[p_{0}, p_{1}\right]$. This follows since $q^{\prime \prime}(p)=0$ and $C^{\prime \prime}(q(p))=0$ for $p \in\left[p_{0}, p_{1}\right]$. Thus, in particular, $\pi^{\prime \prime}\left(p_{0}\right)=2 q^{\prime}\left(p_{0}\right)$.

Finally, from (A.4),

$$
\pi^{\prime \prime \prime}(p)=2 q^{\prime \prime}(p)=0 \text { for } p \in\left[p_{0}, p_{1}\right]
$$

and so $\pi^{\prime \prime \prime}(\tilde{p})=2 q^{\prime \prime}(\tilde{p})=0$ since $\tilde{p} \in\left(p_{0}, p_{1}\right)$. 